\title{
ASCORBIC ACID AND THE GROWTH OF PLANT EMBRYOS
}

\section{By James Bonner and David Bonner}

William G. Kerckhoff Laboratoribs, California Institute Technology

Communicated December 27, 1937

Introduction.-In an earlier paper it has been shown ${ }^{1}$ that excised pea embryos of the variety "Perfection" may be satisfactorily grown upon sterile nutrient medium, particularly if various "accessory growth factors" of known chemical composition are provided. It was shown that there are at least four of these growth factors, one of which is ascorbic acid. It is ascorbic acid with which the present communication is particularly concerned.

There have been, previously, conflicting reports as to the effect of ascorbic acid upon plant growth. Havas, ${ }^{2}$ von Hausen ${ }^{3}$ and Davis, Atkins and Hudson, ${ }^{4}$ among others, have found that ascorbic acid may exert a beneficial effect upon the growth of certain plants. It is of particular importance in the present connection, however, that Kögl and Haagen-Smit, ${ }^{5}$ who grew pea embryos in vitro under conditions similar to those used by the present authors, failed to find any growth factor activity for ascorbic acid. They worked with pea varieties other than "Perfection," and a varietal difference in the ability of pea embryos to cover their ascorbic acid requirements by synthesis might therefore be suspected. It will be shown below that the embryos of different pea varieties do indeed differ widely in their ability to synthesize ascorbic acid from sucrose. It will in addition be shown that those varieties which synthesize the smallest amounts of this substance are those which respond (with increased growth) to its addition to the culture medium. The varieties which synthesize relatively large amounts of ascorbic acid, on the other hand, apparently furnish themselves with sufficient amounts of the substance and do not respond to its addition to the external medium.

Methods.-The nutrient medium used for the culture of the excised embryos was that used in the previous experiments, ${ }^{1}$ which contained, per liter, the following constituents: $\mathrm{Ca}\left(\mathrm{NO}_{3}\right)_{2} \cdot 4 \mathrm{H}_{2} \mathrm{O}, 236 \mathrm{mgs}$. $-\mathrm{MgSO}_{4} \cdot 7 \mathrm{H}_{2} \mathrm{O}$, $36 \mathrm{mgs}$. $-\mathrm{KNO}_{3}, 81 \mathrm{mgs}$. $-\mathrm{KCl}, 65 \mathrm{mgs}$. $-\mathrm{KH}_{2} \mathrm{PO}_{4}, 12 \mathrm{mgs}$. - ferric tartrate, $1.5 \mathrm{mgs}$.- sucrose, $40 \mathrm{gms}$. and agar, $10 \mathrm{gms}$. Fifteen cc. of this medium was placed in each of the $50 \mathrm{cc}$. Erlenmeyer flasks which were used as the culture vessels. $0.75 \mathrm{Mgs}$. of ascorbic acid was added to each culture flask in the ascorbic acid cultures. The pea seeds were sterilized in $95 \%$ alcohol and $0.1 \% \mathrm{HgCl}_{2}$, and were then soaked in sterile water for six hours prior to excision of the embryos. The length of time for which the seeds are soaked is of considerable importance, since with times longer than six hours, increasing amounts of the various accessory growth factors are ap- 
parently mobilized from the cotyledons by the embryo. Twenty embryos were used for each treatment or variety in each experiment, and each experiment consisted of 10 parallel portions, or a total of 200 embryos. The actual culturing was carried out in a special culture room, after which the embryos were grown in a dark room thermostatically controlled at $24 \mathrm{C}$. Ascorbic acid determinations were made by extraction of the tissues with $2 \%$ meta-phosphoric acid in $8 \%$ acetic acid according to the method of Muslin and King, ${ }^{6}$ and subsequent titration of the extract with a standard 2-6-dichlorphenolindophenol solution in a micro-burette.

Growth measurements of the seedling shoots were made weekly for four weeks from the time of excision of the embryos, and the measurements from

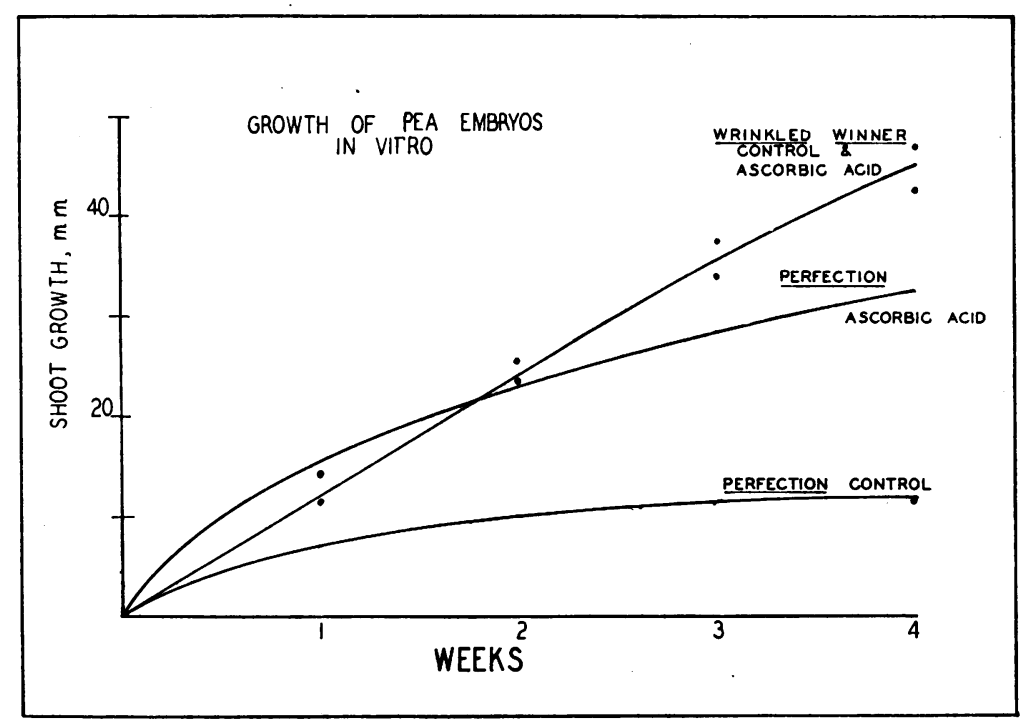

FIGURE 1

The growth rate of pea embryos in vitro, the varieties "Perfection" and "Wrinkled Winner," each with and without the addition of ascorbic acid to the nutrient medium.

a typical experiment are presented in figure 1. Preliminary experiments also showed that the ascorbic acid content rises to a maximum within two weeks and that it remains at approximately this maximum level for the following two weeks. The ascorbic acid determinations were therefore made only on the plants whose growth had been followed for four weeks. This had of course the advantage that the growth measurements and the ascorbic acid determinations were made upon the same individual plants. In the discussion below only the shoots will be considered. It was, however, found that there is a close correlation between the ascorbic acid content of root and shoot. 
Experimental Results.-Nine varieties of pea embryos were compared as to synthesis of and growth response to ascorbic acid. ${ }^{7}$ The length of shoot, response to ascorbic acid and content of ascorbic acid, all at the expiration of four weeks, are summarized for each of these nine varieties in table 1 and presented graphically for two typical varieties in figure 2 . It may be seen at once that the varieties fall sharply into two classes, i.e., those which respond to added ascorbic acid with greatly increased growth, and those which show little or no growth response. Of the latter the variety

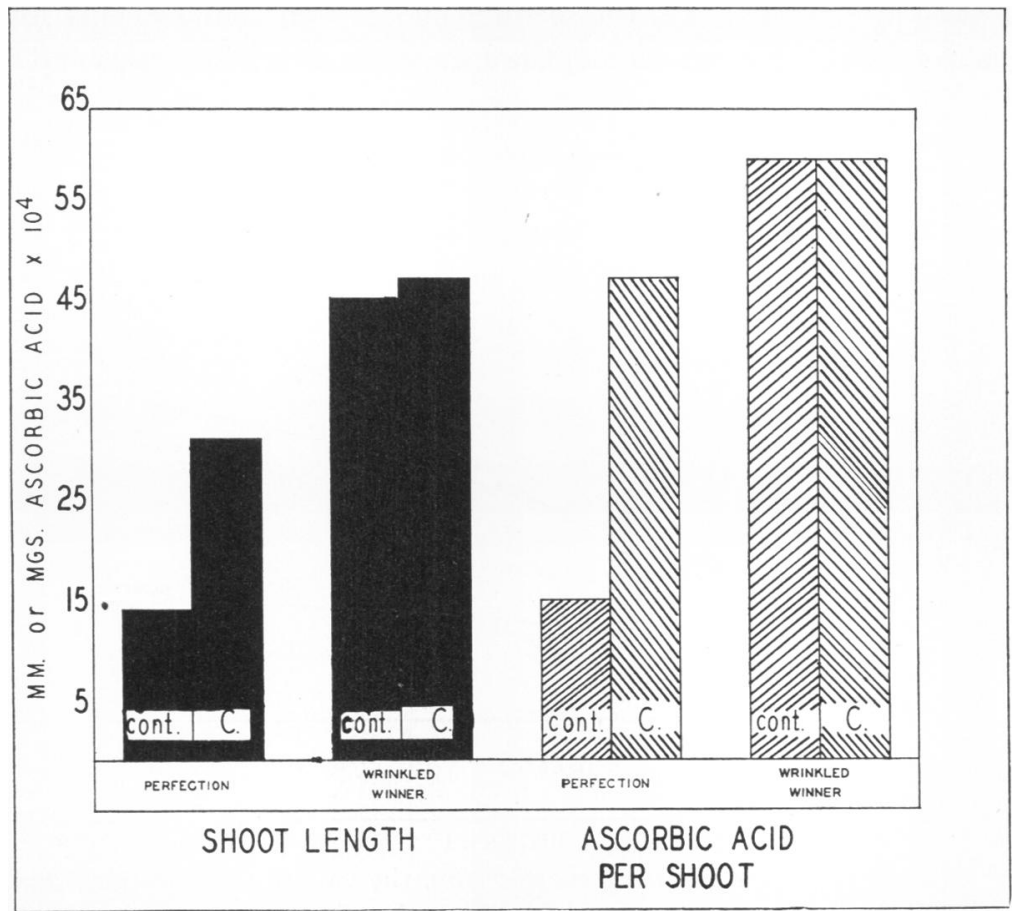

FIGURE 2

The growth and the ascorbic acid content of pea embryos, varieties "Perfection" and "Wrinkled Winner" after four weeks in vitro. "cont." = control cultures, without added ascorbic acid. "C." = cultures receiving ascorbic acid.

"Wrinkled Winner" is the best example, since the four other varieties proved more difficult to grow in vitro and gave rather irregular results. Correlated with growth response to added ascorbic acid is low ascorbic acid content of the variety when it is grown on the vitamin free basic medium. The varieties "Perfection" and "Alaska" which respond vigorously contain less than one-third as much ascorbic acid as embryos of "Wrinkled Winner" which does not respond. Neither "Perfection" nor "Wrinkled 
Winner" embryos contain appreciable amounts of ascorbic acid when they are excised from the seed at the end of six hours' soaking. The above differences of ascorbic acid content of the seedlings must then be due to differences in the ability of the various varieties to synthesize ascorbic acid. We see at once that the fact that some varieties of pea embryos do not respond to ascorbic acid does not by any means justify the conclusion that such embryos do not need this substance. It would rather seem to indicate that such embryos are capable of synthesis of ascorbic acid in quantities sufficient to fulfill their requirements.

Plants which are supplied with ascorbic acid actually take it up and their content of this substance is correspondingly increased above that of control plants, as is also shown in table 1 and graphically in figure 2 . The ascorbic acid content of the variety "Perfection" when supplied with ascorbic acid, is not greatly below that of the variety "Wrinkled Winner" which synthesizes the substance in adequate amounts. Thus, when "Perfection" embryos are supplied with ascorbic acid, their vitamin content as well as their growth rate increases to a level comparable to that of the ascorbic acid "auto-trophic" variety, "Wrinkled Winner."

TABLE 1

Ascorbic Acid Content and Growth Responses of Nine Varieties of Pea EMBRYos in Vitro

\begin{tabular}{|c|c|c|c|c|c|c|c|}
\hline \multirow[b]{2}{*}{ VARIETY } & \multirow{2}{*}{$\begin{array}{l}\text { TOTAL } \\
\text { PLANTS } \\
\text { USED }\end{array}$} & \multicolumn{3}{|c|}{ AVERAGE GROWTH IN } & \multicolumn{3}{|c|}{ SCORBIC ACID PER; } \\
\hline & & CONTROL & $\begin{array}{c}\text { ASCORBI } \\
\text { ACID }\end{array}$ & $\begin{array}{c}(\% \text { OF } \\
\text { CONTROL) }\end{array}$ & $\begin{array}{l}\text { CONTROL } \\
\text { SHOOT }\end{array}$ & $\begin{array}{l}\text { ASCORBIC } \\
\text { SHOOT }\end{array}$ & $\begin{array}{l}\text { WEIGHT, } \\
\text { (CONTROL) }\end{array}$ \\
\hline Perfection & 100 & 15 & 32 & 213 & 0.0016 & 0.0048 & 0.064 \\
\hline Alaska & 40 & 23 & 46 & 200 & 0.0016 & 0.0035 & 0.075 \\
\hline Daisy & 40 & 10 & 17 & 170 & 0.0015 & $\ldots$ & 0.050 \\
\hline British Empire & 40 & 11 & 18 & 163 & 0.0012 & $\cdots$ & 0.054 \\
\hline Delacatesse & 20 & 29 & 33 & 114 & 0.004 & $\cdots$ & 0.138 \\
\hline Little Marvel & 20 & 37 & 38 & 103 & 0.006 & $\ldots$ & 0.120 \\
\hline Laxtons Progress & 20 & 24 & 25 & 104 & 0.006 & $\ldots$ & 0.167 \\
\hline Stratagem & 20 & 22 & 23 & 104 & 0.005 & $\ldots$ & 0.145 \\
\hline Wrinkled Winner & 100 & 46 & 48 & 104 & 0.006 & 0.006 & 0.172 \\
\hline
\end{tabular}

The control embryos of the five varieties which synthesize relatively large amounts of ascorbic acid also grow somewhat better than the control embryos of the four varieties which are ascorbic acid "hetero-trophic," although the variety "Alaska" is apparently an exception. It seems nevertheless that in general, ability to synthesize ascorbic acid is correlated not only with a lack of response to added vitamin, but also with a larger absolute growth in the absence of added vitamin.

As mentioned above, the excised pea embryo is able to respond with increased growth to several different accessory factors, even though one of these factors be added to the medium in the absence of the others. Thus, aneurin (vitamin $\mathrm{B}_{1}$ ) alone acts as an accessory growth factor just as does 
ascorbic acid. ${ }^{1}$ However, the addition of aneurin to the medium considerably increases the amount of ascorbic acid present in the plant, as is

TABLE 2

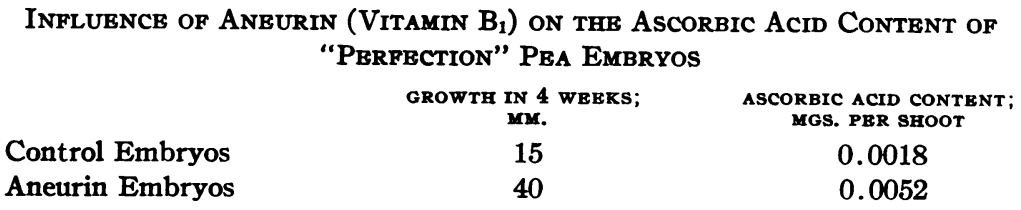

shown in table 2. In this typical experiment there was found to be nearly three times as much ascorbic acid in the plants which received aneurin (0.01 mgs. per culture flask $^{8}$ ) as in those which did not. The nature of this effect cannot as yet be explained, but it is of interest to note that Svirbely ${ }^{9}$ reports that synthesis of ascorbic acid by the rat depends upon an adequate supply of vitamin $B_{1}$.

Discussion.-The point which it is particularly desired to emphasize in the present paper is that an organism will or will not respond to a given accessory growth factor depending, among other things, on $(a)$ the need of the organism for the factor in question, and $(b)$ the ability of the organism to synthesize the substance. The fact that a given organism does not respond to a given growth factor may then mean only that the particular organism is equipped to synthesize it in adequate amounts; it does not necessarily mean, however, that the factor in question plays no rôle in the economy of the organism. This principle has long been familar to the animal physiologists, who realized that the rat, for example, covers its ascorbic acid requirements by synthesis. The same principle has also been demonstrated for the yeasts by Lucas ${ }^{10}$ and others, and more recently for other of the fungi by Kög1 and Fries. ${ }^{11}$ It would seem important that this principle be also recognized in plant physiology, in order that controversies as to the "essential" or "non-essential" nature of the various growth factors be avoided. It has been shown above that plants as closely related as the various varieties of peas differ greatly as to their response to ascorbic acid. For varieties such as "Perfection" and "Alaska" ascorbic acid would seem, superficially, to be more nearly an essential growth factor than for varieties such as "Wrinkled Winner." In reality, however, these varieties differ rather in their ascorbic acid auto-trophism, in their ability to synthesize the substance, and it would seem justifiable to conclude that ascorbic acid is quite as much a growth factor for "Wrinkled Winner" as for "Perfection."12

1 J. Bonner and Grice Axtman, Proc. Nat. Acad. Sci., 23, 453 (1937).

2 L. Havas, Nature, 136, 435 (1935).

${ }^{3}$ S. von Hausen, Biochem. Zeit., 288, 378 (1936).

- W. Davis, G. Atkins and P. Hudson, Ann. Bot. [N. S.], 1, 329 (1937). 
5. Kögl and J. Haagen-Smit, Zeit. Physiol. Chem., 243, 209 (1936).

${ }^{6}$ R. Muslin and G. King, Jour. Biol. Chem., 116, 409 (1936).

${ }^{7}$ For seed of the various pea varieties the authors are greatly indebted to the FerryMorse Seed Co., San Francisco, and to the Calif. Packing Corp., San Francisco.

8 The authors are indebted to the Merck Co., Inc., Rahway, N. J., for the supply of synthetic aneurin.

9 J. Svirbely, Amer. Jour. Physiol., 116, 445 (1936).

${ }^{10}$ G. Lucas, Jour. Phys. Chem., 28, 1180 (1924).

${ }^{11}$ F. Kögl and N. Fries, Zeit. Physiol. Chem., 249, 93 (1937).

12 Published as a report on Work Project No. 6330-6989, Official Project No. 165-036999, conducted under the auspices of the Works Progress Administration. The authors are deeply indebted to Philip Divirian for his able and continuous assistance during the prosecution of this work.

\section{POTENTIALS IN HALICYSTIS AS AFFECTED BY NON-ELECTROLYTES}

\section{By W. J. V. Osterhout}

\section{Laboratorigs OF The Rockefeller Institute for Medical Research}

Communicated December 20, 1937

In diluting the sea water surrounding marine algae it is desirable to add something to maintain the osmotic pressure, otherwise the cells take up water and may burst. Damon ${ }^{1}$ used glycerol for this purpose in experiments on Valonia. He found that the changes in P.D. at $20^{\circ} \mathrm{C}$. obeyed the equation

$$
\text { P.D. }=58 \frac{V_{\mathrm{Cl}}-U_{\mathrm{Na}}}{V_{\mathrm{Cl}}+U_{\mathrm{Na}}} \log \frac{C_{1}}{C_{2}}
$$

where $V_{\mathrm{Cl}}$ and $U_{\mathrm{Na}}$ are the apparent mobilities of $\mathrm{Cl}^{-}$and $\mathrm{Na}^{+}$in the outer protoplasmic surface, $C_{1}$ is the higher and $C_{2}$ the lower concentration of sea water. Putting $C_{\mathrm{Cl}}=1$ he obtained 0.2 for the value of $U_{\mathrm{Na}}$ (on the assumption that $C_{1} \div C_{2}$ was the same in the protoplasmic surface as in the external solution).

The limiting value of the P.D. in this case may be obtained by putting $U_{\mathrm{Na}}=0$. We then obtain $17.4 \mathrm{mv}$. as the limit when $C_{1} \div C_{2}=2$. This value is a little less when we employ activities in place of concentrations. ${ }^{2}$

Similar experiments with Halicystis $^{3}$ yield a different result. In view of the work of Blinks ${ }^{4}$ it was decided to add sufficient $\mathrm{CaCl}_{2}$ and $\mathrm{KCl}$ to the glycerol solution to make the concentration approximately the same as in sea water. The solution contained $1.1 \mathrm{M}$ glycerol $+0.02 \mathrm{M} \mathrm{CaCl}_{2}+$ $0.012 \mathrm{M} \mathrm{KCl}$.

When sea water is diluted with an equal volume of this solution (at $\mathrm{pH}$ 8.2) and is then substituted for natural sea water (at $\mathrm{pH} \mathrm{8.2)} \mathrm{we} \mathrm{find} \mathrm{that} \mathrm{in}$ 